\title{
A new species of the nematode genus Copemania (Nematoda: Trichostron- gylida), parasitic in the western quoll, Dasyurus geoffroii and short-nosed bandicoot, Isoodon obesulus from south-western Western Australia
}

\author{
I. Beveridge ${ }^{1}$ and M.-C. Durette-Desset ${ }^{2}$ \\ ${ }^{1}$ Department of Veterinary Science, University of Melbourne, Veterinary Clinical Centre, \\ Werribee, Victoria 3030, Australia \\ ${ }^{2}$ Département de Sytématique et Evolution, UMR 7138 Systématique, Adaptation, Evolution, \\ associée au CNRS, UMS 0603, Muséum national d'Histoire naturelle, \\ CP 52, 61 rue Buffon, 75231 Paris, France
}

\begin{abstract}
Copemania darwini sp. nov. is described from the small intestine of Dasyurus geoffroii Gould, 1841 (type host) and Isoodon obesulus (Shaw, 1797) from Collie, Western Australia. The new species is distinguished from its only congener, C. obendorfi Durette-Desset and Beveridge, 1981, found in Dasyurus maculatus (Kerr, 1792) in Victoria in the shape of the spicules, which lack a hook-shaped termination to the principal branch in the new species and in the vulvar appendages which are linguiform in the new species. The new species represents the first record of the genus in Western Australia and is one of the few trichostrongyloid nematodes known from Australian marsupials which occur in both dasyurids and peramelids.
\end{abstract}

Keywords: Copemania, new species, Nematoda, Trichostrongylida, Dasyurus, Isoodon, morphology, taxonomy.

\section{INTRODUCTION}

Trichostrongyloid nematodes are ubiquitous parasites of the stomachs and small intestines of vertebrates (Durette-Desset 1985). However, the study of the Australian representatives of this group of parasites is in its infancy, with many species in museum collections awaiting description (Spratt et al. 1991). Australian monotremes and marsupials are hosts to several families of trichostrongyloid nematodes including three endemic families, Nicollinidae, Mackerrastrongylidae and Herpetostrongylidae, which are of particular interest from the perspective of parasite evolution given the relative isolation of the Australian monotreme and marsupial radiations. Parasite lineages found within marsupials in Australia appear to have multiple phylogenetic origins with families linked to parasites of South American marsupials (Herpetostrongylidae) (Humphery-Smith 1983) or monotremes (Nicollinidae, Mackerrastrongylidae) (Durette-Desset 1983; Beveridge and Spratt 1996), thereby potentially providing examples of major groups of nematode parasites evolving by mechanisms of co-speciation and host-switching (Beveridge and Spratt 1996).
The trichostrongyloid fauna of Western Australian marsupials is particularly poorly studied, with only a limited number of genera and species recognised from the state thus far, these being: Austrostrongylus thylogale Johnston and Mawson, 1940 in Setonix brachyurus (Quoy and Gaimard, 1830), A. incurvispiculum Beveridge and Durette-Desset, 1986 in Macropus fuliginosus (Desmarest, 1817), Profilarinema hemsleyi DuretteDesset and Beveridge, 1981 in Trichosurus vulpecula (Kerr, 1792), Mackerrastrongylus mawsonae Inglis, 1986 in Isoodon obesulus (Shaw, 1797), Nicollina ridei Inglis, 1986 in Tachyglossus aculeatus (Shaw and Nodder, 1792) and Sprattellus waringi (Inglis, 1986) in Dasyurus geoffroii Gould, 1841 (Thomas 1959; Inglis 1968; Durette-Desset and Beveridge 1981a; Beveridge and Durette-Desset 1986).

In this paper, we report the occurrence of an additional genus, Copemania Durette-Desset and Beveridge, 1981, in Western Australia, represented by a new species which occurs both in the dasyurid D. geoffroii and in the peramelid I. obesulus in the south-west of the state.

\section{METHODS}

Specimens examined came from the collections 

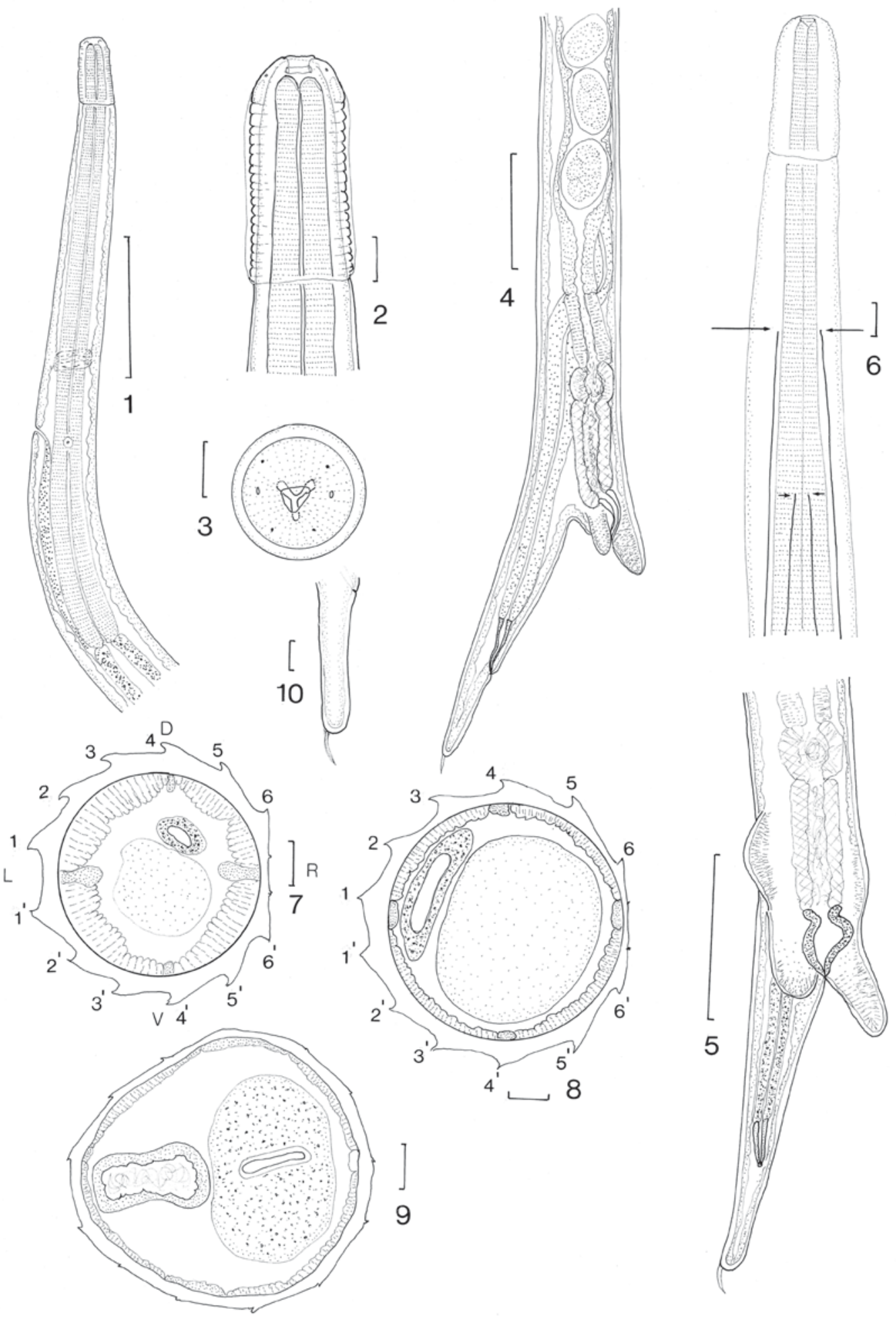

Figures 1-10 Copemania darwini sp. nov. from Dasyurus geoffroii, all illustrations from paratypes: 1, anterior end, female, lateral view; 2, cephalic extremity, lateral view, male; 3, cephalic extremity, apical view (sex of specimen not known); 4, female tail, right lateral view; 5, female tail, sub-ventral view; 6, anterior extremity, male, showing origins of synlophe ridges on right hand side of body, ridges $5,5^{\prime}$, long arrows, ridges $6,6^{\prime}$, short arrows; 7 , synlophe in transverse section, male, $33 \%$ of length from anterior end; 8 , synlophe in transverse section, female, $48 \%$ from anterior end; 9, synlophe in transverse section, female, at level of ovejector, showing diminution in size of body ridges; 10, female tail, right lateral view. Scale-bars: 1, 4, 5, $0.1 \mathrm{~mm} ; 2$, 3, 6, 7-10, $0.01 \mathrm{~mm}$. Abbreviations: D, dorsal; V, ventral; L, left; R, right. Body ridges are numbered from left to right with ventral ridges indicated by a prime. The tiny ridges on the right hand side of the synlophe have not been numbered. 
of the South Australian Museum, Adelaide (SAMA) and were examined microscopically after clearing in lactophenol. Drawings were made with the aid of a drawing tube attached to an Olympus $\mathrm{BH}$ microscope. Measurements were made with an ocular micrometer and are presented as the range followed by the mean and number of specimens measured in parentheses. Terminology of the synlophe and the description of the bursal rays follow Durette-Desset (1983). Body ridges in transverse sections are numbered from left to right.

\section{Phylum Nematoda}

\section{Family Nicollinidae Durette-Desset and Chabaud, 1981}

\section{Genus Copemania Durette-Desset and Beveridge, 1981}

Copemania Durette-Desset and Beveridge, 1981: 66.

\section{Type species}

Copemania obendorfi Durette-Desset and Beveridge 1981, by original designation.

\section{Copemania darwini sp. nov.}

Figures 1-15

\section{Material examined}

Holotype

Australia: Western Australia: $\mathrm{O}^{\lambda}$, Collie $\left(33^{\circ} 22^{\prime} \mathrm{S}\right.$, $\left.116^{\circ} 09^{\prime} \mathrm{E}\right), 25$ May 1992, R. Hobbs. Host: Dasyurus geoffroii Gould, 1941 (Marsupialia: Dasyuridae); localisation: small intestine (SAMA 45395).

\section{Allotype}

Australia: Western Australia: + , same data as holotype (SAM 45396).

\section{Paratypes}

Australia: Western Australia: 13 $\hat{\jmath}, 15$ ㅇ, same data as holotype (SAMA 45397, 32983, 32987).

\section{Additional material studied}

Australia: Western Australia: 11 के, 9 , Collie $\left(33^{\circ} 22^{\prime} \mathrm{S}, 116^{\circ} 09^{\prime} \mathrm{E}\right)$, October 2004, R. Brazelle, host: Isoodon obesulus (Shaw, 1797), (Marsupialia: Peramelidae); localisation: small intestine (SAM 45393, 45394).

Prevalence: present in three of nine D. geoffroii and two of six I. obesulus examined.

\section{Diagnosis}

Small nematodes; cephalic vesicle present; buccal capsule reduced, without teeth; synlophe with ridges oriented from right to left, axis of orientation perpendicular to sagittal axis; male with rays 2 of bursa highly divergent; complex spicules with three points; female monodelphic; vulva subterminal; terminal spine on tail; parasites of dasyurid marsupials.

\section{Description}

Nematodes straight or slightly coiled. Mouth triangular, lips absent; 4 cephalic papillae and two amphids present; labial papillae not seen; buccal capsule tiny, annular; oesophageal tooth absent; cephalic vesicle present with 15-20 annulations; cervical collar absent; oesophagus claviform. Nerve ring in mid-oesophageal region; deirid and excretory pore immediately posterior to nerve ring.

\section{Synlophe}

In both sexes, ridges originate in anterior oesophageal region, ridges $2-5$ appear 60 posterior to cephalic vesicle, ridges 1 and 6 appear 85 posterior to cephalic vesicle; ridges disappear immediately anterior to bursa in male, at level of ovejector in female. Synlophe symmetrical in relation to frontal axis with 12 prominent cuticular ridges ( 6 dorsal, 6 ventral). 2 tiny, right lateral ridges more prominent in male than in female. Ridges decreasing slightly in size from left to right on both sides. Right lateral ridges tiny and orientated perpendicularly to body surface, barely visible in female. Axis of orientation orientated from right to left, inclined at $90^{\circ}$ to sagittal axis.

\section{Male}

Holotype: length $4.1 \mathrm{~mm}$, maximum width 55; cephalic vesicle 50 long; oesophagus 400 long; nerve ring and excretory pore 200 and 210 from anterior end respectively; spicules 105 long, gubernaculum 80 long.

Paratypes: (measurements of 5 specimens, means in parentheses) length 3.9-4.3 (4.15) $\mathrm{mm}$, maximum width 55-60 (57); cephalic vesicle 50-60 (55) long; oesophagus 390-430 (410) long; nerve ring and excretory pore 200-210 (204) and 200-280 (241) from anterior end respectively; spicules 115-130 (123) long, gubernaculum 75-80 (78) long.

Bursa very slightly asymmetrical with right side marginally larger and rays slightly thicker; pattern of rays of type 1-3-1 for both lobes. Rays 5 and 6 recurved dorsally. Right ray 6 broader than left ray 6. Dorsal lobe well-marked; rays 8 slender, arising from the same common trunk as rays 6, parallel to rays 6 for most of their length. Dorsal ray short and broad, divided at two-thirds into two branches. Each branch divides into three tips: rays 9 (externo-dorsal), rays 10 (interno-dorsal) and phasmids (median). Rays 9 arising on dorsal ray after its division. Rays 9 thicker and slightly shorter 
than rays 10 . Genital cone prominent; papilla 0 in form of elongate projection, papillae 7 elongated, paired; transverse membrane with central V-shaped projection ventral to cone. Spicules light brown in colour, short, terminating in three points, interno-ventral branch longest; externo-lateral branch median slightly longer than interno-lateral; gubernaculum elongate, broader but less well sclerotised anteriorly.

\section{Female}

Allotype: length $5.4 \mathrm{~mm}$, maximum width 60; cephalic vesicle 50 long; oesophagus 430 long; nerve ring and excretory pore 225 and 250 from anterior end respectively; tail 75 long; vulva to posterior end 170; vagina vera 35 , vestibule 55 long, sphincter 30 long, infundibulum 110 long; egg 65 x 40; 11 unembryonated eggs in uterus.

Paratypes: (measurements of 5 specimens, means in parentheses) length 4.25-5.43 (4.80) mm, maximum width 60-70 (66); cephalic vesicle 50-60 (53) long; oesophagus 350-410 (397) long; nerve ring and excretory pore 190-195 (193) and 210-250 (230) from anterior end respectively; tail 63-80 (73) long with terminal spike 8-13 (11) long; vulva to posterior end 185-225 (204); vagina vera 30-50 (39), vestibule 45-80 (65) long, sphincter 30-45 (37) long; infundibulum 70-160 (113) long, uterus 440-530 (470) long; eggs 55-65 (60) x 35-40 (38); 9-12 (10) eggs in uterus.

Monodelphic, vulva near posterior end; vulva with 2 projections on either side, projection on left hand side large, linguiform; projection on right hand side smaller, less prominently ornamented with striations; cuticular flange present anterior to right projection, with prominent striae; tiny flange present on left hand side, identifiable mainly by more prominent striae. Tail tip blunt with prominent terminal spike.

\section{DISCUSSION}

The new species described here clearly belongs to the genus Copemania as it has a synlophe with ridges oriented from right to left and an axis of orientation perpendicular to the sagittal axis as well as a cephalic vesicle, a reduced buccal capsule without teeth, rays 2 of the bursa highly divergent from the remaining rays and complex spicules with three points. All of these are characteristics of Copemania (see Durette-Desset and Beveridge 1981b) and exclude its allocation to any other genus. Until now, this genus has remained monotypic, with the only other species, C. obendorfi Durette-Desset and Beveridge, 1981, being reported from Dasyurus maculatus (Kerr, 1792) in Victoria. The species describe here differs distinctly from $C$. obendorfi in the shape of the spicules of the male, with the longest branch having a hook-shaped termination in C. obendorfi, which is lacking in C. darwini and most particularly in the morphology of the female. In C. obendorfi, the vulva has two cuticular enlargements on either side, but in C. darwini, at least one of these enlargements is linguiform providing a highly characteristic feature in the females. In addition, the infundibulum is recurrent in the C. obendorfi, but not in the new species and the tail is trilobed in C.obendorfi, but not in $C$. darwini. This series of morphological differences provide little doubt that the species described here is new.

The finding of $C$. darwini in D. geoffroyii parallels the occurrence of its congener $C$. obendorfi in $D$. maculatus in Victoria. However, the unexpected aspect of this study was the finding of the parasite in I. obesulus from the same area. Peramelid marsupials tend to have a distinctive trichostrongyloid nematode fauna compared with dasyurids (Spratt et al. 1991) with the exception of the gastric-inhabiting species Peramelistrongylus skedastos Mawson, 1960, which has a broad host range in both peramelid and dasyurid marsupials (Spratt et al. 1991).

Since none of the life cycles of the Australian trichostrongyloid nematodes has been elucidated, no explanation can currently be advanced as to why this genus has been found in bandicoots in Western Australia but not in eastern Australia in areas where dasyurids and bandicoots co-occur.

The Nicollinidae is a small trichostrongyoid family containing three genera, Nicollina Baylis, 1930, parasitic in echidnas (eight species), Batrachonema Yuen, 1965 in Malaysian amphibians (one species) and Copemania (two species) in dasyurid marsupials (Durette-Desset 1983). While relationships within the family are not well-defined, in the Australian region, DuretteDesset and Beveridge (1981b) interpreted the genus Copemania as being derived from Nicollina, suggesting that dasyurids had acquired this genus by host switching from nematodes already present in monotremes.

\section{ACKNOWLEDGEMENTS}

We wish to thank the Australian Biological Resources Study for financial support and Russ Hobbs (Murdoch University) and Rob Brazelle (DEC, Collie) for collecting the material used in this paper.

\section{REFERENCES}

Beveridge, I. and Durette-Desset, M-C. (1986). New species of Austrostrongylus Chandler, 1924 (Nematoda, Trichostrongyloidea) from Australian marsupials, with a redescription of $A$. minutus Johnston \& 

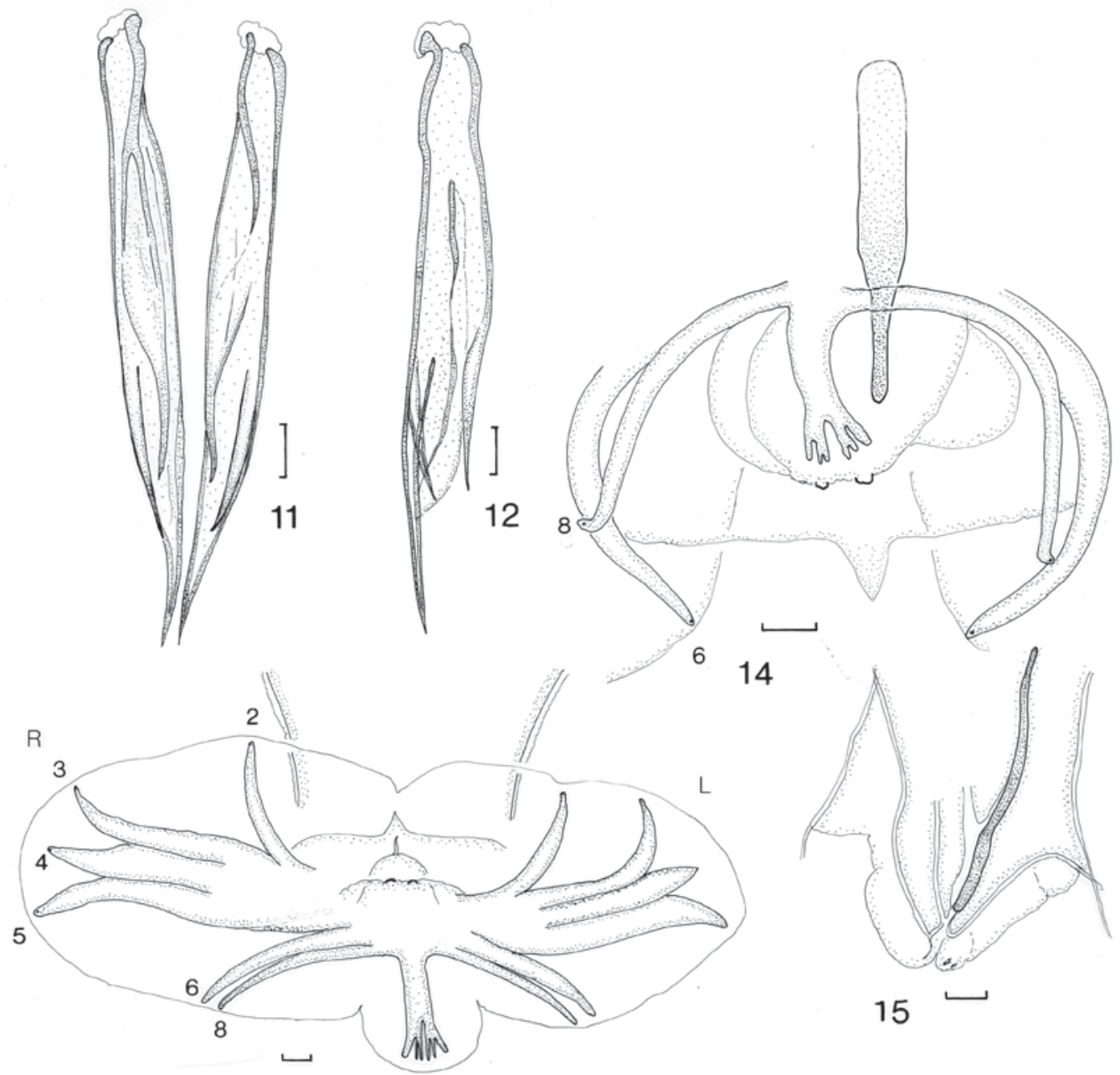

13

Figures 11-15 Copemania darwini sp. nov. from Dasyurus geoffroii, all illustrations from paratypes: 11, spicules in situ, dorsal view; 12, spicule in situ, lateral (external) view, ventral aspect on left hand side; 13, bursa, apical view; 14 , dorsal ray and gubernaculum, dorsal view; 15, gubernaculum and genital cone, left lateral view. Scalebars: $0.01 \mathrm{~mm}$. Abbreviations: L, left; R, right.

Mawson, 1938, and description of a new genus, Sutarostrongylus. Bulletin du Muséum National d' Histoire Naturelle, Paris, $4^{\circ}$ série 8: 145-170.

Beveridge, I. and Spratt, D.M. (1996). The helminth parasites of Australasian marsupials: origins and evolutionary biology. Advances in Parasitology 37: 136-254.

Durette-Desset, M.-C. (1983). Keys to genera of the super-family Trichostrongyloidea. In: Commonwealth Institute of Helminthology Keys to the Nematode parasites of Vertebrates. Part 10. Commonwealth Agricultural Bureaux: Farnham Royal.

Durette-Desset, M.-C. (1985). Trichostrongyloid nematodes and their vertebrate hosts: reconstruction of the phylogeny of a parasitic group. Advances in Parasitology 24: 239-306.

Durette-Desset, M-C. and Beveridge, I. (1981a). Peramelistrongylus Mawson, 1960 et Profilarinema n. gen. Nématodes trichostrongylides paraissant faire transition entre les Strongyloidea et le genre atypique Filarinema Moennig, 1929. Annales de Parasitologie Humaine et Comparée 56: 183-191.

Durette-Desset, M-C. and Beveridge, I. (1981b). Copemania obendorfi n. gen., n. sp. Nématode Trichostrongylö̈de parasite d'un marsupial australien. Annales de Parasitologie Humaine et Comparée 56: 63-66.

Humphery-Smith, I. (1983). An hypothesis on the evolution of the Herpetostrongylidae (Trichostrongyloidea: Nematoda) in Australian marsupials, and their relationships with Vianaiidae, parasites of South-American marsupials. Australian Journal of Zoology 31: 931-942.

Inglis, W.G. (1968). The geographical and evolutionary relationships of Australian trichostrongyloid parasites and their hosts. Journal of the Linnean Society (Zoology) 47: 327-347.

Spratt, D.M., Beveridge, I. and Walter, E.L. (1991). A catalogue of Australasian monotremes and marsupials and their recorded helminth parasites. Records of the South Australian Museum, Monograph Series 1: 1-105

Thomas, P.M. (1959). Some nematode parasites from Australian hosts. Transactions of the Royal Society of South Australia 82: 151-162.

Manuscript received 23 March 2009; accepted 13 August 2009. 